\title{
Continuing Use of Withdrawal as a Contraceptive Method in Iran
}

\author{
Akbar Aghajanian \\ Department of Sociology \\ Fayetteville State University \\ Fayetteville, NC 28301 \\ aaghajanian@uncfsu.edu
}

\section{Amir H. Mehryar}

Population Studies and Research Center

Ministry of Science, Research and Technology

Tehran, Iran

Bahram Delavar

Ministry of Health and Medical Education

Tehran, Iran

\section{Shahla Kazemipour}

Population Studies and Research Center

Ministry of Science, Research and Technology

Tehran, Iran

\section{Hassan Eini Zinab}

Population Studies and Research Center

Ministry of Science, Research and Technology

Tehran, Iran 


\begin{abstract}
Since its establishment in 1989, the family planning program of Iran has taken great strides in raising contraceptive prevalence rate and reducing fertility. The most recent national survey conducted in 2000 indicated a contraceptive prevalence rate of 74 and a TFR of 2.0 for the country as whole. This paper reviews the latest data on the extent of use of withdrawal by Iranian couples and identifies the social and demographic characteristics of women relying on this method. It is shown that women using this traditional method are more likely to be urban, come from the more developed provinces, and have higher levels of education. The experience of unintended pregnancy among withdrawal user is not more than the women who use modern contraceptives such as the pill.
\end{abstract}

Key Words: Iran, Family Planning, Contraceptive Use, Withdrawal,

\title{
Résumé
}

Depuis sa création en 1989, le programme de planification familiale en Iran a réussi à mettre en hausse la prévalence des contraceptifs et à réduire le taux de fécondité. La dernière enquête nationale conduite en l'an 2000 indique un taux de prévalence des contraceptifs à 74 et un ISF (indice synthétique de fécondité) de 2.0 dans tout le pays. Cet article révise les dernières données sur l'étendue de la méthode du retrait chez les couples iraniens et identifie les caractéristiques sociales et démographiques des femmes qui se fient à cette méthode. Il est démontré que les femmes qui se servent de cette méthode traditionnelle ont tendance à être urbaines, issues de provinces plus développées et ont un niveau d'étude plutôt élevé. Les incidences de grossesses non désirées chez les femmes qui se servent de la méthode du retrait ne sont pas plus élevées que pour celles qui se servent de méthodes contraceptives plus modernes telles que la pilule.

Mots-clés: Iran, Family Planning, Contraceptive Use, Withdrawal, 
Continuing Use of Withdrawal as a Contraceptive Method in Iran

\section{Introduction}

Withdrawal or coitus interruptus is one of the oldest methods of contraception which would seem to have been known and used by couples in many societies throughout the recorded history of mankind (Himes, 1936; Santow, 1993, 1995; Rogow and Horowitz, 1995). It has well recorded history in the Islamic world where discussions of the use of this method (referred to as $a z l$ ) can be traced back to the time of Prophet Mohammad (Musallam, 1983; Omran, 1992). In addition to repeated references to its wide use by Islamic jurists and physicians writing in Arabic, philosophical and medical texts written by Iranian physicians in Persian bear witness to the widespread practice of the method in this part of the Islamic world (Elgood, 1949). In fact, AlGhazali's famous book Alchemy of Happiness "Kimyaye Saadat" includes one of the most detailed and best argued discussions on contraception in general and coitus interruptus ("azl") in particular written by classic Islamic thinkers on the subject (Mehryar, 2005).

The tradition and use of withdrawal goes beyond the Islamic world. The most recent data presented in Table 1 shows the prevalence rate of this method in a large number of countries. There are a number of countries including Iran in the West and Central Asia that have 10 percent and higher withdrawal users among married women in the age groups 15-49. Compared with the world estimates of 3 percent of married women in age group 15-19, Iran has a high rate of withdrawal users.

In Iran until mid 1950s when population and family planning became matters of national concern and public discourse, the method would seem to have been practiced widely by couples. In 1967 the first national family planning program was established. By 1978 when the Islamic revolution succeeded, the program had managed to cover just over a third (37 percent) of eligible couples, most of them living in urban areas (Aghajanian and Mehryar, 1999). The local surveys carried out in early 1970s (Gillespie, et al, 1972) showed that almost one third of couples using contraceptives were relying on withdrawal. During the first decade after the revolution (1979-1988) the family planning program was suspended and government policy stressed early marriage and reproduction as basic Islamic values. Nevertheless, the Ministry of Health continued to offer such contraceptives as pills, IUDs, and condoms through its Maternal and Child Health clinics. In addition motivated couples were able to

obtain contraceptives from the private health sector. Condoms were in fact easily available through drug stores or even major supermarkets. These services were however far from sufficient to meet the needs of all couples. Thus we speculate that coitus interruptus must have played a major role during this 
Aghajanian, Akbar, A. H. Mehryar, B. Delavar, S. Kazemipour and H. E. Zinab

period. The aim of this descriptive paper is to review the available data on the use of withdrawal as a contraceptive method in Iran and to document the share of this method in the contraceptive mix of Iranian couples.

Table 1

Countries with 10 Percent Contraceptive or High Withdrawal Rate for Selected Countries: 2005

\begin{tabular}{lc}
\hline \multicolumn{1}{c}{ Country } & Percent \\
\hline & \\
Slovakia & 32.1 \\
Armenia & 31.9 \\
Albania & 31.8 \\
Azerbaijan & 30.6 \\
Romania & 28.7 \\
Bosnia-Herzegovina & 26.9 \\
Bahrain & 26.3 \\
Turkey & 24.4 \\
Ukraine & 19.5 \\
Italy & 17.5 \\
Iran & 17.4 \\
Mauritius & 16.1 \\
Japan & 15.3 \\
Moldova & 13.9 \\
Bulgaria & 12.8 \\
Lebanon & 11.8 \\
Serbia and Montenegro & 11.3 \\
Poland & 11.1 \\
Georgia & 10.5 \\
& \\
World weighted average & 3.0 \\
& \\
\hline
\end{tabular}


Continuing Use of Withdrawal as a Contraceptive Method in Iran

\section{Method and Material}

In 1976, the Statistical Center of Iran conducted the Iran Fertility Survey as part of the World Fertility Survey Program (Aghajanian, Gross, and Lewis, 1993). The tabulations from this survey provided the 1976 data used in this paper. From 1989 to 1997, the Ministry of Health and Medical education conducted KAP surveys using a large urban and rural sample of ever married women. The reported sample size for these surveys were 10,000 rural and 10,000 urban households in each year. The results from these surveys were presented annually in July when the department participated in World Population Day. We had access to published tables from these data for various years. These published results only show the rates but not the numbrs based on which the rates were calculated. The most recent data are from 2000 Demographic and Health Survey of Iran. Designed and implemented by Iranian experts, the Demographic and Health Survey of Iran (DHSI-2000) is the first effort to apply a locally adapted version of the internationally known DHS instrument to a large sample of households representing the urban and rural population of all provinces of the country. The DHSI-2000 is probably unique for its entire reliance on national expertise and advice in survey design, implementation, and coverage of a huge sample. A total of 114,000 households with a total population of about 475,000 were chosen in a way that it is possible to carry out separate analysis for the urban and rural areas of each of the 28 provinces of Iran as well as the Tehran Metropolitan Area. The financial support of the project by the UNFPA and UNICEF and their participation in the various stages of the survey contributed significantly to the quality of the project implementaton.

The DHSI-2000 was developed over a three year period. The Population and Family Health Department of the Ministry of Health and Medical Education (MOHME) was assigned the overall responsibility for the design and implementation of the survey. To ensure the technical quality of the survey and make its results acceptable to academic researchers as well as specialized agencies, a steering committee consisting of academic demographers, staff members from the Statistical Center of Iran as well as staff from the Civil Registration Organization, and researchers with long tracks of research and teaching on population and reproductive health, oversaw implementation of the project at various stages.

The sampling frame for the survey was based on the 1996 census. The availabitity of data for provincial level estimation of various indicators was carefully considered in the sampling process. The sample was designed to select 400 primary sampling units (200 urban and 200 rural) from each of the 28 provinces of the country. In Tehran province, 400 primary sampling units were selected from the urban and rural areas outside the Tehran Metropolitan Area. 
Aghajanian, Akbar, A. H. Mehryar, B. Delavar, S. Kazemipour and H. E. Zinab

Tehran Metropolitan Area was treated as a separate urban unit represented by an independently selected sample of 2000 households. The actual sample size achieved included 113,957 households (57,968 urban and 55,989 rural). The response rate was 97.5 percent in urban areas and 99.0 percent in rural areas. In addition to the heads of households (or another adult member of the household) who provided the household level information, a total of 91,604 ever married women of reproductive age were interviewed (46,916 urban and 44,688 rural). These women provided data on reproductive health and other issues concerning women and young children. For this paper some data come from the published tables of this survey (MOHME, 2003). We also requested some tabulations from the microdata file, for this paper.

\section{Findings}

Trends in the prevalence rate of withdrawal as a contraceptive method in Iran are reported in Table 2. The table shows the contraceptive prevalence rate measured as the percent of women who were not pregnant and used contraceptive at the time of survey. According to the Iran Fertility Survey, by 1976, that is a decade after the establishments of the pre-Revolutionary family planning program in 1967, only about a third of the eligible married couples were using any contraceptive. The rate was much higher (54 percent) in urban areas than the rural $(20$ percent $)$-at the time rural population counted for over half of the population of Iran. Close to one-fifth (17.3 percent) of urban and three percent of rural couples reported using withdrawal as their means of pregnancy prevention. It can be speculated that the high rate of withdrawal among urban population has been the mechanism behind observed difference between fertility level in urban and rural areas when public family planning programs did not existed.

The KAP survey conducted by the MOHME in 1989, shortly before the revival of the family planning program, revealed a surprisingly high rate of withdrawal as a method of contraceptive among urban and rural couples. The survey revealed a significant rise in the proportion of couples relying on withdrawal method during the period 1976 to 1989 . The rise in use of this contraceptive method was from 17.3 percent to 27 percent in urban areas and from 3.1 percent to 8 percent in rural areas. The increasing trend in the rate of withdrawal slowed down as official national family planning intensified and choice of contraceptive methods expanded during 1990s. However, by 2000 the prevalence rate of withdrawal among women currently married, 15 to 49 years old, was 21 percent in urban areas and 10 percent in rural areas. 
Continuing Use of Withdrawal as a Contraceptive Method in Iran

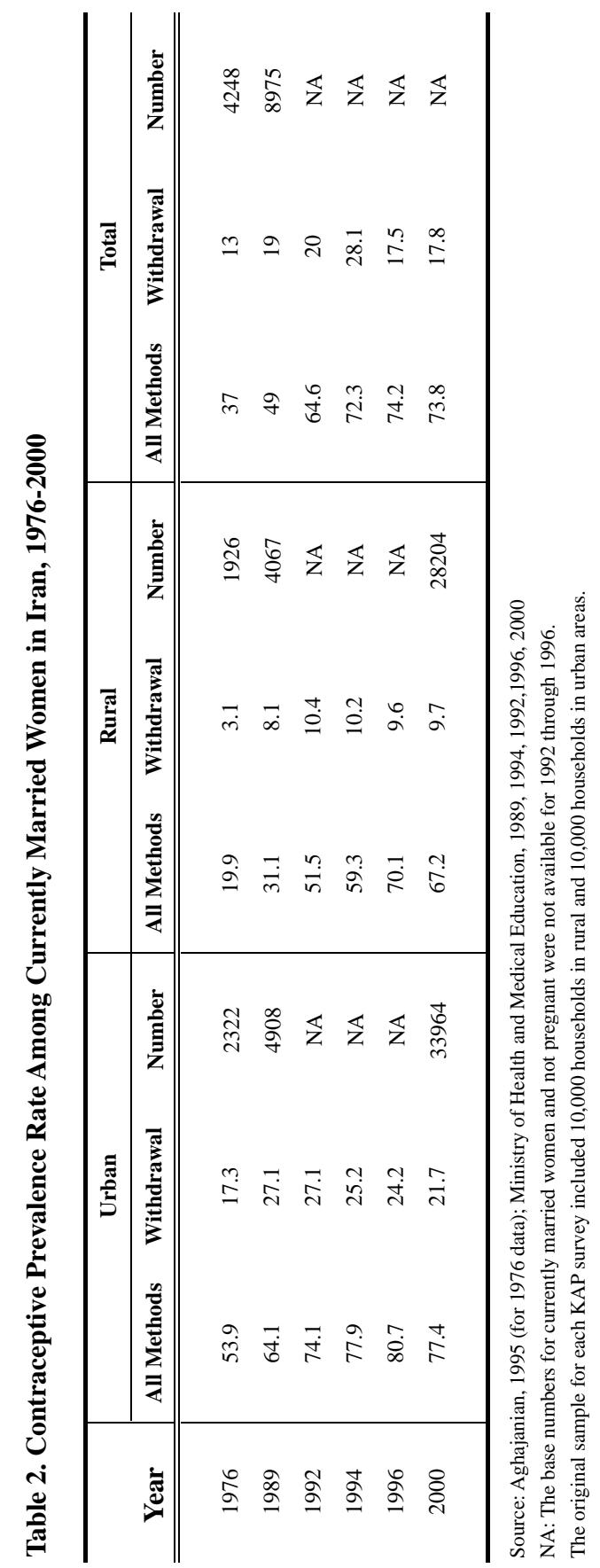


Aghajanian, Akbar, A. H. Mehryar, B. Delavar, S. Kazemipour and H. E. Zinab

The role of withdrawal as a method of contraceptive is much more impressive when considered in the context of contraceptive mix. Table 3 shows the share of withdrawal in contraceptive mix in rural and urban Iran. According to the 2000 Survey, 28 percent of the contraceptive users in urban areas reported withdrawal as their method of current use. In rural areas the rate was about 15 percent. In looking at the trend in the mix of contraceptive use it is obvious that whenever the government sponsored family planning program and distribution of modern contraceptives were weak, the share of withdrawal in the contraceptive mix has been increasing. For example, during the 1980s over two fifths (42.3 percent) of urban couples using any method were relying on withdrawal. These figures might be taken as an indication of the high demand for family planning and the important role played by withdrawal during the period when other methods were not readily available.

The data presented in Tables 2 and 3 indicate that withdrawal method is definitely an urban method. As expected a high correlation between the percent of urban population in a province and the percent of withdrawal users among couples using contraceptives, was observed $(r=.90, \mathrm{df}=16, \mathrm{p}<.01)$. Similarly the higher the percentage of women with higher education, the higher the rate of withdraw users in the province $(\mathrm{r}=.60, \mathrm{df}=16, \mathrm{p}<.01)$. A number of other provincial development indicators such as female literacy rate, infant mortality, and human development index showed the same strong and significant correlation with withdrawal rate across the provinces-correlations are not shown here to avoid redundancy.

Table 3

Urban and Rural Proportional Distribution of Contraceptive Withdrawal in Iran: 1976-2000

\begin{tabular}{cccc}
\hline Year & $\begin{array}{c}\text { Urban } \\
\text { \% }\end{array}$ & $\begin{array}{c}\text { Rural } \\
\boldsymbol{\%}\end{array}$ & $\begin{array}{c}\text { Total } \\
\boldsymbol{\%}\end{array}$ \\
\hline 1976 & 32.1 & & \\
1989 & 42.3 & 15.5 & 35.1 \\
1992 & 36.4 & 25.8 & 38.5 \\
1994 & 32.3 & 20.2 & 31.0 \\
1996 & 30.0 & 17.2 & 38.9 \\
2000 & 28.0 & 13.3 & 23.6 \\
& & 14.4 & 24.1 \\
\hline
\end{tabular}

Source: See Table 2 . 
Continuing Use of Withdrawal as a Contraceptive Method in Iran

Table 4 is based on tabulation of the individual level data from IDHS 2000 and it shows the rate of withdraw users among various groups of married women 1549 yeas old in urban and rural areas. The individual level data presented in Table 4 reveals the pattern observed at the macro level. The rate of withdrawal use is higher among the more educated women. The relationship between age of marriage and withdrawal use is positive. The higher the age of marriage is, the higher the rate of using withdrawal. On the other hand older women report a lower rate of using withdrawal.

When the share of withdrawal in the contraceptive mix is as high as the level observed in Iran, a very important concern is the contribution of the method to unwanted pregnancies. To examine this issue we calculated the distribution of women who reported being pregnant at the time of survey, by their contraceptive status at the time of pregnancy. This analysis was only related to the women who said they were using some type of contraceptive when the pregnancy happened. Table 5 shows the distribution of these women by the type of contraceptive they were using.

In urban areas the failure rate of withdrawal is about 2 percent higher than the failure rate for the pill. In rural areas, the failure rate of pill is much higher than the failure rate of withdrawal. Overall these data does not show that in Iran, the failure rate of withdrawal is higher than the failure rate of the pill which is the most popular method of contraception. It seems that couples who use the withdrawal method are very much committed to prevention than the pill users, especially in the rural areas.

\section{Discussion}

Despite the historical roots of withdrawal in the Islamic culture, the method does not seem to enjoy wide popularity in contemporary Muslim majority countries of North Africa, Middle East, and Asia. Azerbaijan, Bahrain, Turkey, Iran and Lebanon are the only five out of 26 Muslim majority countries of North Africa and Asia with substantially high withdrawal use rate. The continuing use of withdrawal as one of the main form of traditional contraceptives by a large proportion of Iranian couples is worth attention on several grounds. First, the method is being used despite the easy availability of a wide mix of modern methods offered freely by the national family planning program. A perusal of the evidence on regional and urban-rural variations in withdrawal rate clearly indicate that the continued use of this method is by no 
Table 4

Withdrawal Prevalence Rate by Socio-demographic Characteristics among Currently Married Women who were not Pregnant in Iran: 2000

\begin{tabular}{|c|c|c|c|c|c|}
\hline & \multirow[b]{2}{*}{ Variables } & \multicolumn{4}{|c|}{ Prevalence Rate* } \\
\hline & & Urban & Numbers & Rural & Numbers \\
\hline \multicolumn{6}{|l|}{ Age } \\
\hline & $15-19$ & 38.5 & 1021 & 25.1 & 1168 \\
\hline & $20-24$ & 28.2 & 4289 & 17.1 & 3987 \\
\hline & $25-29$ & 26.1 & 6350 & 14.3 & 5401 \\
\hline & $30-34$ & 24.1 & 6950 & 11.4 & 5398 \\
\hline & $35+$ & 21.7 & 15340 & 9.7 & 12225 \\
\hline \multicolumn{6}{|l|}{ Age at Marriage } \\
\hline & 19 or less & 23.1 & 23777 & 13.1 & 21897 \\
\hline & $20-24$ & 29.2 & 8143 & 14.9 & 5174 \\
\hline & $25+$ & 36.1 & 2044 & 15.1 & 1103 \\
\hline \multicolumn{6}{|l|}{ Education } \\
\hline & None & 11.9 & 27322 & 6.9 & 12402 \\
\hline & Some primary & 22.5 & 10909 & 15.8 & 10868 \\
\hline & Some secondary & 28.7 & 6149 & 24.2 & 2863 \\
\hline & High School Diploma & 34.3 & 7840 & 35.5 & 1640 \\
\hline & Some college & 35.3 & 2417 & 29.1 & 212 \\
\hline \multicolumn{6}{|c|}{ Migration status } \\
\hline & None Migrant & 23.9 & 29217 & 11.9 & 28018 \\
\hline & Provincial migrants & 32.5 & 1759 & 21.4 & 666 \\
\hline & Other migrants & 23.7 & 2912 & 17.7 & 60 \\
\hline Total number** & & 33964 & & & \\
\hline
\end{tabular}

*Prevalence rate is measured by percent of women in each category of the variable, reporting using withdrawal contraceptive.

** Number of women 15-49 who were married and were not pregnant at the time of the interview. The sum in each variable does not add up to total due to missing cases in the independent variable. Source: Tabulation from the micro data of IDHS 2000 
Continuing Use of Withdrawal as a Contraceptive Method in Iran

Table 5

Distribution of Women with Unintended Pregnancy by Contraceptive in Iran: 2000

\begin{tabular}{lccc}
\hline \multicolumn{1}{c}{ Year } & Urban & Rural & Total \\
\hline Pill & 36.6 & 58.1 & 47.7 \\
Condom & 13.3 & 8.0 & 10.6 \\
Withdrawal & 38.5 & 21.9 & 29.9 \\
Other Methods & 11.6 & 12.0 & 11.8 \\
Number & 571 & 611 & 1181 \\
\hline
\end{tabular}

Chi-square test statistically significant at .001

Source: Requested tabulation from the micro data of IDHS 2000.

means due to lack of access to information about, and supplies of more modern methods. On the contrary, better educated, urban and more prosperous regions and couples are very much overrepresented among the users of this method. The regional pattern of withdrawal rate, based on provincial data, suggest that cultural differences may be as important as differences in socioeconomic development in determining the use of this method of family planning. In Iran the provinces with the highest withdrawal rates are mainly concentrated in north central areas.

\section{Acknowledgement:}

Akbar Aghajanian was on research release supported by Grant P20 MD001089 from the department of Health and Human Services, when this paper was being prepared. We are thankful to the anonymous reviewers' for helpful comments. 
Aghajanian, Akbar, A. H. Mehryar, B. Delavar, S. Kazemipour and H. E. Zinab

\section{References:}

Aghajanian, A., Gross, A., and Lewis, S.M. 1993. "Evaluation of Iran Fertility Survey," Working paper 93-2. University of Washington, Center for Studies in Demography and Ecology.

Aghajanian, A., \& Mehryar, A. H.1999. "Fertility, Contraceptive Use and Family Planning Program Activity in the Islamic Republic of Iran, 19761996," International Family Planning Perspectives, 25: 98-105.

Elgood, C. 1970. Safavid medical Practice. London: Luzac and Company Ltd.

Glillespie, R., Lieberman, S., Loghmani, 1972. Studies in Family Planning, 4, 73-100.

Himes, N.E. 1970. Medical History of Contraception. New York: Schocken Books.

Musallam, B.F. 1983. Sex and Society in Islam. Cambridge: Cambridge University Press

Mehryar, A. 2005. "Shiat ideology and family planning," in Jones, G. and Karim, M. (Eds), Islam, the State and Population. London: Oxford University Press.

Ministry of Health and Medical Education 2003. Report of Iran 2000 Demographic and Health Survey. Tehran, Iran: Ministry of Health and Medical Education.

Omran, A.R. 1992. Family Planning in the Legacy of Islam. New York: Routledge.

Rogow, D. and Horowitz, S. 1995. "Withdrawal: A Review of Literature and Agenda for Research," Studies in Family Planning, 23:140-153.

Santow, G. 1993. "Coitus Interruptus in the Twentieth Century," Population and Development Review, 19:767-792.

Santow, G. 1995. "Coitus Interruptus and the Control of Natural Fertility," Population Studies, 49:19-43.

WWW.PBR.Org. 2006. Population Data sheet database. Visited June 1, 2006. 